\title{
Textural properties of poly(glycidyl methacrylate): acid-modified bentonite nanocomposites
}

\author{
M. Žunić • A. Milutinović-Nikolić • A. Nastasović • \\ Z. Vuković • D. Lončarević • I. Vuković • K. Loos • \\ G. ten Brinke $\cdot$ D. Jovanović
}

Received: 21 September 2012/Revised: 25 December 2012/ Accepted: 24 January 2013/

Published online: 5 February 2013

(C) Springer-Verlag Berlin Heidelberg 2013

\begin{abstract}
The aim of this study was to obtain enhanced textural properties of macroporous crosslinked copolymer poly(glycidyl methacrylate-co-ethylene glycol dimethacrylate) by synthesizing nanocomposites with acid-modified bentonite. Nanocomposites were obtained by introducing various amounts of acid-modified bentonite $\left(\mathrm{B}_{\mathrm{A}}\right)$ into the reaction system. All samples were characterized by attenuated total reflectance infrared spectroscopy, scanning electron microscopy, transmission electron microscopy (TEM), mercury intrusion porosimetry, and low temperature physisorption of nitrogen. The FTIR and TEM analysis confirmed incorporation of $\mathrm{B}_{\mathrm{A}}$ into the copolymer structure and the successful formation of nanocomposites. TEM images confirmed formation of nanocomposites having both intercalated and exfoliated acid-modified bentonite in copolymer matrix. A significant increase of specific surface area, pore volume, and porosity of the nanocomposites in comparison to the copolymer were obtained. The difference between textural properties of nanocomposites with different amounts of incorporated acidmodified bentonite was less prominent.
\end{abstract}

Keywords Suspension copolymerization · Poly(GMA-co-EGDMA) · Nanocomposites · Bentonite · Porosity

\footnotetext{
M. Žunić $(\bowtie) \cdot$ A. Milutinović-Nikolić · Z. Vuković · D. Lončarević · D. Jovanović Department of Catalysis and Chemical Engineering, University of Belgrade, Institute of Chemistry, Technology and Metallurgy, Njegoševa 12, Belgrade 11000, Republic of Serbia e-mail: marija.zunic@nanosys.ihtm.bg.ac.rs
}

\author{
A. Nastasović \\ Department of Chemistry, University of Belgrade, Institute of Chemistry, Technology and \\ Metallurgy, Njegoševa 12, Belgrade 11000, Republic of Serbia \\ I. Vuković $\cdot$ K. Loos · G. ten Brinke \\ Department of Polymer Chemistry, University of Groningen, Zernike Institute for Advanced \\ Materials, Groningen, The Netherlands
}




\section{Introduction}

The study of polymer nanocomposites has become one of the main research subjects in polymer science within the last years [1-4]. Different types of nanoparticles have been used in the preparation of these materials, but layered silicates, such as montmorillonite and other types of clay minerals, are still the most studied ones [5-7]. The polymer clay nanocomposites (PCN's) are materials usually expected to present many improved properties, such as mechanical, thermal, and barrier, among others, in comparison to the pure polymers and even to their microcomposite counterparts [3, 8-10]. The dramatic improvement in physical properties of these materials can be produced by just adding a small fraction of clay to a polymer matrix $[3,11,12]$.

The phyllosilicates have large internal surface and have tendency to agglomerate rather than to disperse homogeneously in a matrix. In order to incorporate them into polymer matrix often additional cations are introduced between the crystalline layers of clay mineral and the obtained organobentonites are used for PCN's synthesis [13-15]. In these cases, the growing polymer chains are closely attached (grafted) onto the nanoparticles and act as compatibiliser and matrix material at the same time. This scheme cannot be applied to all material combinations, specially for complex synthesis systems. Attempts to incorporate nanoparticles in a matrix polymer simply by a surface modification of the particles using the ionic interaction with surfactant molecules gained only a moderate success or failed completely [16, 17].

The most common PCN's are obtained by the following processing techniques: in situ polymerization [17-19], solution casting [12] and melt mixing [5, 20]. Suspension copolymerization was seldom used for PCN's synthesis [21]. In general, two idealized PCN structures are possible: intercalated and exfoliated [8, 22, 23]. In practice, the real structure of a nanocomposite is more complex, including the coexistence of exfoliated, intercalated, and immiscible clay particles [24, 25]. Nevertheless, these systems may still exhibit substantial physical property enhancements [21]. Mainly these PCN's have nonporous structure.

The aim of presented investigation was to synthesize porous PCN's based on poly(GMA-co-EGDMA).

The porous polymer particles are usually prepared by suspension polymerization in which the polymerization mixture consists of monomer mixture (monovinyl and divinyl monomer, i.e., crosslinking agent), initiator and inert component (called porogen, porogenic mixture, or pore forming agent). The presence of the inert solvent is crucial for the preparation of macroporous polymers [26-28].

Macroporous crosslinked polymers are efficient materials for many separation processes, and therefore, they are widely used as starting material, for ion exchange resins and as specific sorbents [29, 30]. The application and efficiency of porous polymers is strongly influenced by pore size and distribution [31]. Therefore, control over pore formation of macroporous copolymers by introducing inorganic filler is challenging task. To our knowledge, we were the first to report the preparation of porous PCN's of poly(GMA-co-EGDMA) by radical suspension copolymerization [32, 33]. Acid-modified bentonite was added to a previously optimized reaction mixture for the synthesis of macroporous crosslinked copolymer poly(glycidyl methacrylate-co-ethylene glycol dimethacrylate) [34]. The influence 
of the amount of acid-modified bentonite introduced into the reaction mixture on the tailoring of textural properties of poly(GMA-co-EGDMA)-based nanocomposites was investigated.

\section{Experimental}

\section{Materials}

Bentonite clay was obtained from the coal and bentonite mine Bogovina (Serbia). It was crushed, ground, and sieved through a $74-\mu \mathrm{m}$ sieve. Using acid-modified clay in nanocomposite synthesis was proven to have greater impact on textural properties than using raw clay [33]. According to our previous findings [35] the acid activation with $3 \mathrm{M} \mathrm{HCl}$ provides acid-modified clay with the best combination of preserved crystalline structure and developed textural properties. Therefore, acid-modified clay in such manner was chosen to be used in nanocomposite synthesis. Acid modification of this clay with $3 \mathrm{M} \mathrm{HCl}$ was realized at $90{ }^{\circ} \mathrm{C}$ for $2 \mathrm{~h}$ and stirring in a glass reactor equipped with a reflux condenser. The mass ratio of the acid solution and the clay was $4: 1$. After modification, the suspension was filtrated under vacuum. The filtration cake was rinsed with distilled water at $80{ }^{\circ} \mathrm{C}$ until the filtrate was $\mathrm{Cl}^{-}$ and/or $\mathrm{Fe}^{3+}$ free (tested with $\mathrm{AgNO}_{3}$ and $\mathrm{K}_{3}\left[\mathrm{Fe}(\mathrm{CN})_{6}\right]$, respectively). The sample was further dried to constant mass at $110{ }^{\circ} \mathrm{C}$ and reground to pass through a $74-\mu \mathrm{m}$ sieve and denoted $\mathrm{B}_{\mathrm{A}}$ [32]. The chemical composition, morphologic and textural properties of modified bentonite were previously reported [35, 36]. The chemical composition (mass\%) was: $\mathrm{SiO}_{2}-63.46 ; \mathrm{Al}_{2} \mathrm{O}_{3}-14.8 ; \mathrm{Fe}_{2} \mathrm{O}_{3}-6.14 ; \mathrm{MgO}-1.79$; $\mathrm{CaO}-0.29 ; \mathrm{Na}_{2} \mathrm{O}-0.27 ; \mathrm{K}_{2} \mathrm{O}-0.96 ; \mathrm{TiO}_{2}-0.45$. The ignition loss was 11.8 mass\%.

All the chemicals employed for synthesis of the copolymer and the nanocomposites were analytical grade products and used as received. The monomers were glycidyl methacrylate, GMA (Fluka) and ethylene glycol dimethacrylate, EGDMA (Merck). Cyclohexanol (Merck) and tetradecanol (Merck) were used as inert components. Poly $\left(N\right.$-vinyl pyrrolidone) (PVP-Kollidone 90, BASF with $M_{w}=1 \times 10^{6} \mathrm{~g} / \mathrm{mol}$ ) was used as the stabilizer in the suspension copolymerization and $2,2^{\prime}$-azobis (2-methylpropionitrile) AIBN (Merck) was used as the reaction initiator.

\section{Synthesis of poly(GMA-co-EGDMA)}

Macroporous poly(GMA-co-EGDMA) was prepared by radical suspension copolymerization of GMA and EGDMA, in the presence of an inert component (80 wt\% of cyclohexanol and $20 \mathrm{wt} \%$ tetradecanol). The organic phase containing the monomer mixture (20.8 $\mathrm{g}$ of GMA and $13.8 \mathrm{~g}$ of EGDMA), AIBN as an initiator $(0.35 \mathrm{~g})$ and $45.4 \mathrm{~g}$ of inert component $(36.3 \mathrm{~g}$ of cyclohexanol and $9.1 \mathrm{~g}$ of tetradecanol) was suspended in the aqueous phase consisting of $240.0 \mathrm{~g}$ of distilled water and $2.4 \mathrm{~g}$ of PVP. The copolymerization was performed at $70{ }^{\circ} \mathrm{C}$ for $2 \mathrm{~h}$ and at $80{ }^{\circ} \mathrm{C}$ for $6 \mathrm{~h}$ in a two-necked round-bottom flask $\left(500 \mathrm{~cm}^{3}\right)$ with a stirring rate of $300 \mathrm{rpm}$. After completion of the reaction, the copolymer particles were washed with 

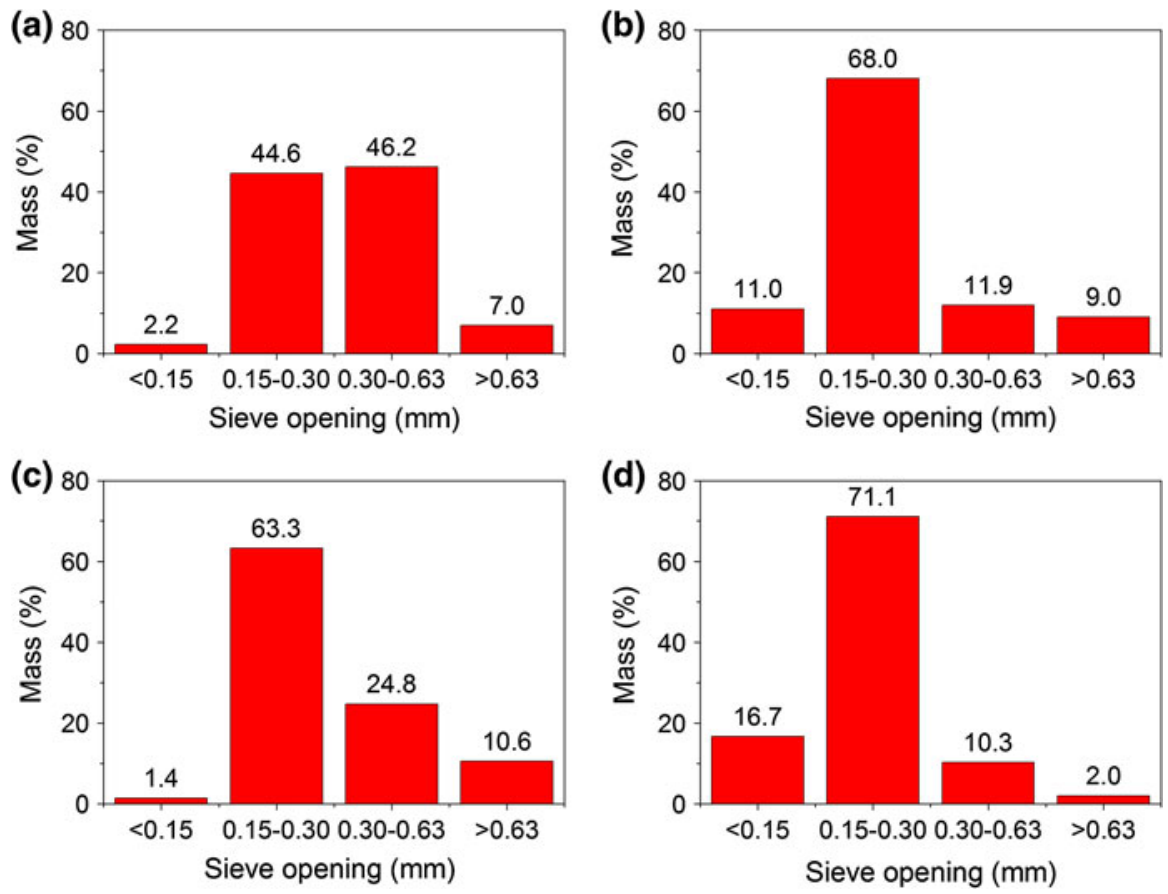

Fig. 1 Histograms for sieve analysis of: a CP, b CP-5B $B_{A}, \mathbf{c} C P-10 B_{A}$, d CP-15B

water and ethanol, kept in ethanol for $12 \mathrm{~h}$, dried at $40{ }^{\circ} \mathrm{C}$ and purified by Soxhlet extraction with ethanol. The obtained copolymer sample was denoted as CP [37].

Synthesis of nanocomposites

The suspension copolymerization method described in the previous section was also used for the preparation of the nanocomposites, but in these cases additional 5, 10 and 15 mass $\%$ of $\mathrm{B}_{\mathrm{A}}$ were added into the reaction mixture. Therefore, 1.75, 3.50 and $5.25 \mathrm{~g}$ of $\mathrm{B}_{\mathrm{A}}$ were suspended in $60 \mathrm{~cm}^{3}$ of distilled water and stirred with a magnetic stirrer overnight at room temperature. This suspension was mixed with a solution of $2.4 \mathrm{~g}$ PVP in $180 \mathrm{~cm}^{3}$ of distilled water, before adding it to the mixture of monomers and inert component. The reaction conditions were the same as for the copolymer synthesis as outlined above. The obtained copolymer and nanocomposites were sieved with $0.15,0.30$ and $0.63 \mathrm{~mm}$ sieves. The results of sieve analysis are given in Fig. 1.

The synthesis of copolymer was optimized in order to predominantly obtain particles with diameter in $0.15-0.30 \mathrm{~mm}$ range. The incorporation of bentonite filler improved beads distribution favoring beads having diameter in $0.15-0.30 \mathrm{~mm}$ range. This bead fraction abundance increased from approx. 45 mass $\%$ for copolymer up to more than 70 mass $\%$ for $C P-15 B_{A}$. With the increase of introduced $\mathrm{B}_{\mathrm{A}}$ the bead size 
shifted toward smaller fraction and improved uniformity. The observed tendency is desirable since the copolymer beads within this range were proven to be the most suitable for further application as sorbents [38-42] and/or enzyme support [43]. Therefore, only the fraction with particle diameters between 0.15 and $0.30 \mathrm{~mm}$ was used for further investigation. The obtained nanocomposites beads were denoted as $\mathrm{CP}-5 \mathrm{~B}_{\mathrm{A}}, \mathrm{CP}-10 \mathrm{~B}_{\mathrm{A}}$ and $\mathrm{CP}-15 \mathrm{~B}_{\mathrm{A}}$ in accordance with the mass $\%$ of $\mathrm{B}_{\mathrm{A}}$ introduced in reaction system.

\section{Characterization methods}

The copolymer and nanocomposites samples were analyzed using several techniques.

The attenuated total reflectance (ATR) infrared (FTIR) spectra were recorded on a Thermo Nicolet 6700 FT-IR Spectrometer in the spectral range 4,000-400 $\mathrm{cm}^{-1}$ with the Smart Orbit Diamond ATR accessory.

SEM microphotographs were obtained using a JSM-6610LV microscope, after coating with a thin layer of gold under reduced pressure (LEICA EM SCD005). Transmission electron microscopy (TEM) analysis was performed on a Philips CM10 transmission electron microscope operating at an accelerating voltage of $100 \mathrm{kV}$. Loaded copolymer particles were embedded in an epoxy resin (Epofix, Electron Microscopy Sciences) and cured overnight at $40{ }^{\circ} \mathrm{C}$. The samples were subsequently microtomed to a thickness of about $80 \mathrm{~nm}$ using a Leica Ultracut UCT-ultramicrotome and a diatome diamond knife at room temperature. The microtomed sections were floated on water and subsequently placed on copper grids. Multiple images of samples were recorded on a Gatan slow-scan CCD camera.

For analysis of textural properties two complementary methods were used: mercury intrusion porosimetry and low temperature physisorption of nitrogen. The first method enables the detection from macropores down to larger mesopores, while latter provides the most reliable results for pores in the micro and mesopore regions [44]. The high pressure mercury intrusion porosimeter (Carlo Erba Porosimeter 2000) operating in the interval 0.1-200 MPa, enabled an estimation of the pores in the interval 7.5-15000 $\mathrm{nm}$. Preparation of the samples was performed at room temperature and a pressure of $0.5 \mathrm{kPa}$ using Macropores unit 120, Carlo Erba. The Milestone 200 software was used in order to analyze textural properties, i.e., specific surface area according to $\mathrm{Hg}$-porosimetry $\left(S_{\mathrm{Hg}}\right)$, total pore volume $\left(V_{\mathrm{p}}\right)$, porosity $(P)$, the most dominant diameter in macroporous region $\left(d_{\max }\right)$.

Nitrogen adsorption-desorption isotherms were determined on a Sorptomatic 1990 Thermo Finnigan instrument at $-196{ }^{\circ} \mathrm{C}$. The samples were outgassed for $5 \mathrm{~h}$ at $p \approx 10^{-3} \mathrm{~Pa}$. The outgassing temperatures were $50{ }^{\circ} \mathrm{C}$ for all samples. The specific surface area of the samples, $S_{\mathrm{BET}}$, was calculated according to the Brunauer, Emmett, Teller method [45]. Total pore volume was calculated according to the Gurvitch method for $p / p_{0}=0.98[44,45]$. Pore volume in mesopore region were obtained according to the Barrett, Joyner, Halenda method [44]. 


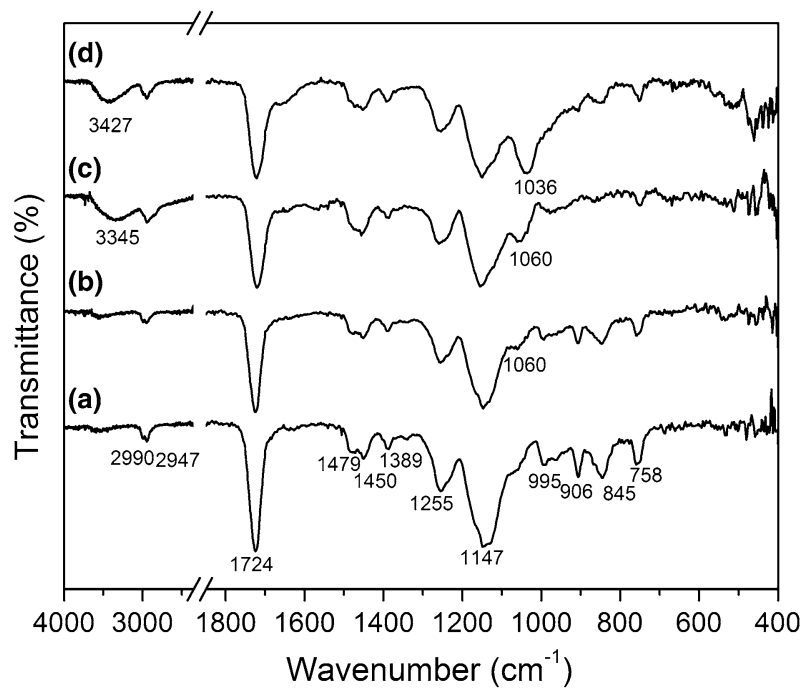

Fig. 2 ATR-FTIR spectra of: a CP, b CP-5B A $_{A}$ c CP-10B, d CP-15B ${ }_{A}$

\section{Results and discussion}

Infrared spectroscopy

IR spectroscopy was performed in order to confirm the incorporation of inorganic filler into the nanocomposite. FTIR spectra of the investigated samples are presented in Fig. 2.

In the FTIR spectrum of the copolymer, the bands can be assigned to the epoxy ring vibrations, $\delta(\mathrm{C}-\mathrm{O}-\mathrm{C})$ at 906,845 and $758 \mathrm{~cm}^{-1}$; the ester group vibrations, $v(\mathrm{C}-\mathrm{O})$ at 1,255 and $1,147 \mathrm{~cm}^{-1}$ and $v(\mathrm{C}=\mathrm{O})$ at $1,724 \mathrm{~cm}^{-1}$, and the methylene group vibrations, $\delta(\mathrm{CH})$ at 1479,1450 and $1389 \mathrm{~cm}^{-1}$ and $v(\mathrm{CH})$ at 2,990 and $2,947 \mathrm{~cm}^{-1}[46,47]$.

The FTIR bands present in the spectrum of the copolymer were also identified the in spectra of the synthesized nanocomposites. The amount of inorganic part in the nanocomposites was very small, but nevertheless it caused some changes in the FTIR spectra. The bands originated from the copolymer matrix somewhat changed in their relative intensity as well as in their shape. The most dramatic change was observed in two regions: $3,700-3,100 \mathrm{~cm}^{-1}$ and $1,060-1,030 \mathrm{~cm}^{-1}$. In the spectra of nanocomposites a wide band in the interval $3,700-3,100 \mathrm{~cm}^{-1}$, can be assigned to the $v(\mathrm{OH})$ vibrations $[48,49]$. The intensity of this band was almost negligible for $\mathrm{CP}-5 \mathrm{~B}_{\mathrm{A}}$. On the other hand, both $\mathrm{CP}-10 \mathrm{~B}_{\mathrm{A}}$ and $\mathrm{CP}-15 \mathrm{~B}_{\mathrm{A}}$ have a well expressed wide band in this interval. In the FTIR spectra of the nanocomposites, in the range of 1,060-1,030 $\mathrm{cm}^{-1}$ a band appears that increased with the increase of incorporated bentonite and shifted toward smaller wavenumbers. This band can be attributed to the $\mathrm{Si}-\mathrm{O}-\mathrm{Si}$ stretching vibrations originated from bentonite [32, 50]. The incorporation of bentonite in copolymer decreased the intensity of bands assigned to the epoxy ring vibrations 906 , 

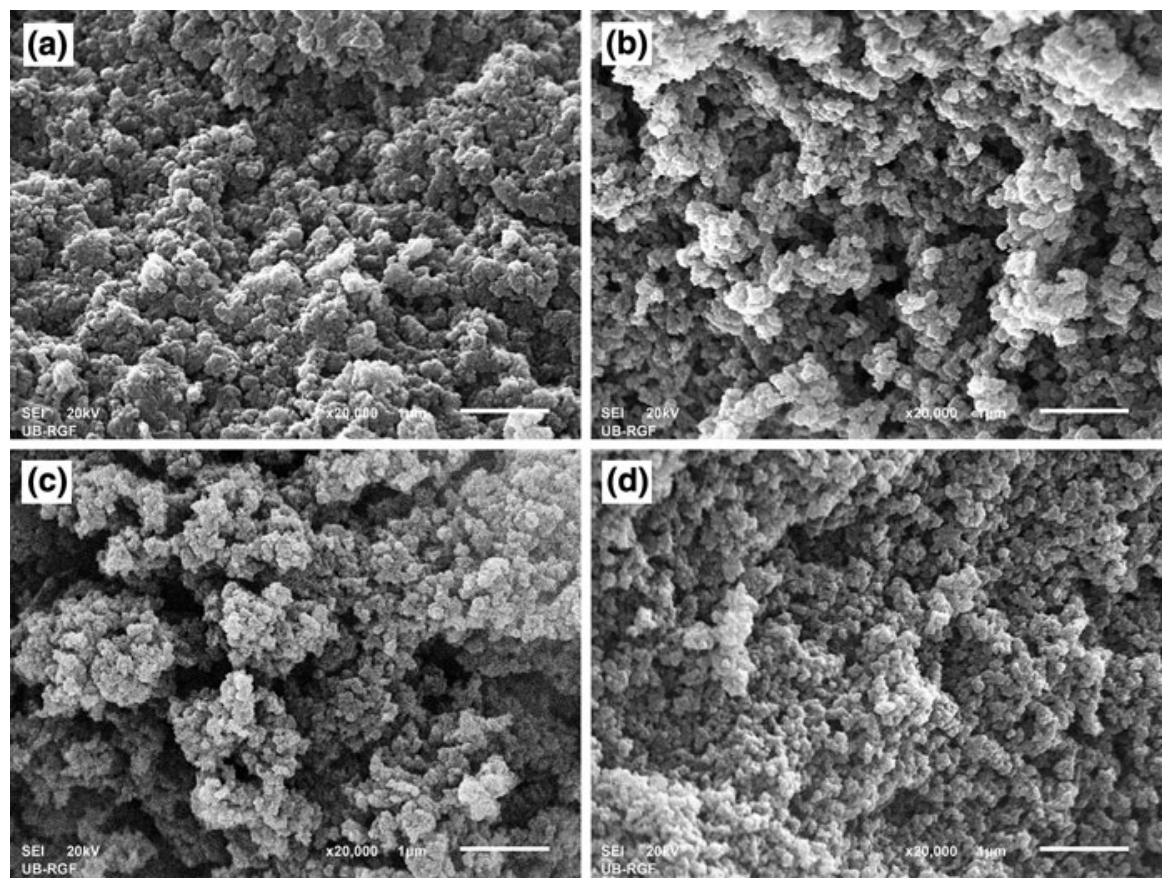

Fig. 3 SEM microphotographs of: a CP, b CP-5B $\mathrm{B}_{\mathrm{A}}, \mathbf{c}$ CP-10B $\mathrm{B}_{\mathrm{A}}, \mathbf{d}$ CP-15B $\mathrm{B}_{\mathrm{A}}$

845 , and $758 \mathrm{~cm}^{-1}$ in spectra of composites due to partial ring opening in the presence of acid-modified bentonite. Ring opening in acidic media is expected phenomena [51].

Scanning electron microscopy

The cross-section of the synthesized samples was observed by SEM. Microphotographs of all samples taken under the same magnification $(\times 20,000)$ are presented in Fig. 3.

Macroporous structure appears as the result of phase separation and crosslinking, which occurs during the polymerization of a monomer mixture (monovinyl and divinyl monomers, i.e. crosslinking agent), initiator and inert component (porogen) [52]. The point at which phase separation occurs, and consequently, porosity of the synthesized copolymer, is determined by copolymer/inert component interactions as well as the amount of crosslinking agent and inert component [29].

The addition of bentonite in reaction system designed for synthesis of macroporous poly(GMA-co-EGDMA) causes a shift in phase separation point and promotes formation of pores with smaller diameters in nanocomposite samples. With the increase of amount of introduced bentonite into reaction mixture this effect is less expressed and this finding is confirmed with results of analysis of textural properties. 

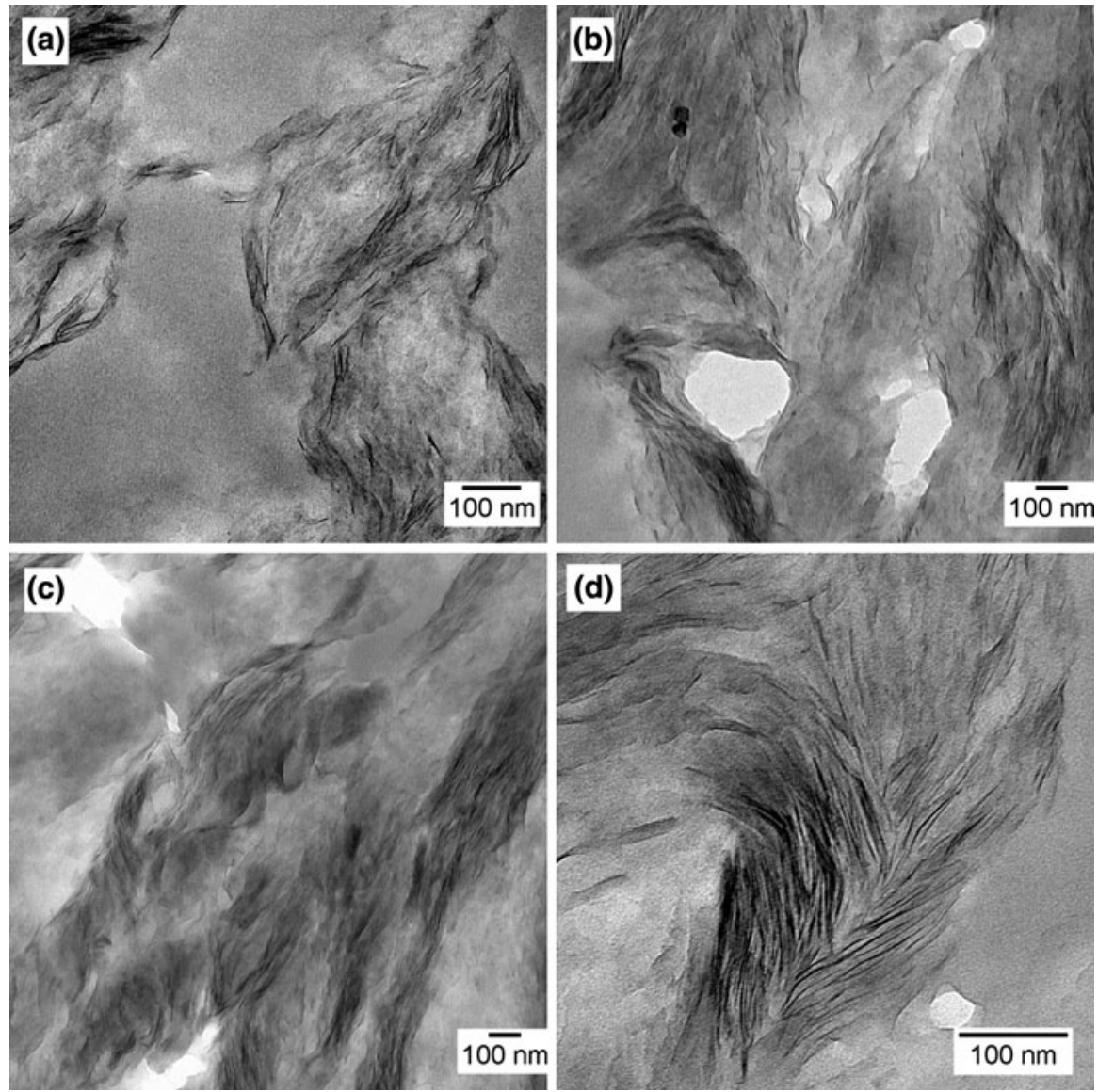

Fig. 4 TEM microphotographs of: a CP-5B $B_{A}$ b CP-10B ${ }_{A}, \mathbf{c} C P-15 B_{A}$, d CP-5B $B_{A}$

\section{Transmission electron microscopy}

Selected TEM microphotographs of microtomed nanocomposites are depicted in Fig. 4.

The TEM images at a lower magnification (Fig. 4a-c) clearly showed the existence of bentonite regions (dark lines) within the copolymer structure, confirming that nanocomposites were successfully synthesized. The very bright white regions confirmed the existence of pores and demonstrated the variety of their sizes and shapes. With the increase of incorporated bentonite the intensity of dark regions increased and the bentonite layers overlapped making it difficult to distinguish the type of nanocomposite that was synthesized. According to literature it is hard to find an unambiguous conclusion for the type of nanocomposites produced namely intercalated or exfoliated. The obtained materials can usually be described as a dispersion of intercalated and exfoliated aggregates in the matrix [13, 24]. 

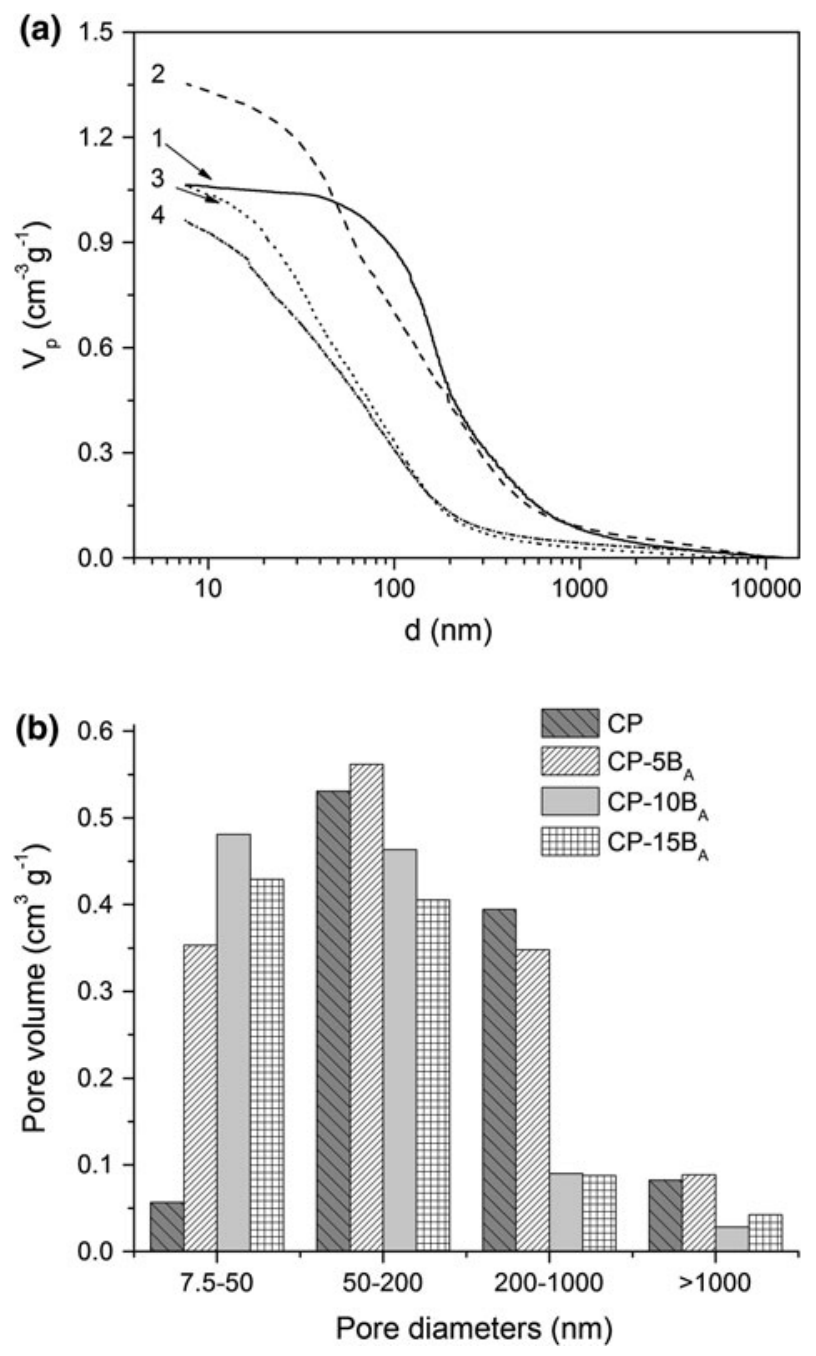

Fig. 5 Result obtained by mercury intrusion porosimetry. a Cumulative pore-size distribution curves of the investigated samples: $1 \mathrm{CP}, 2 \mathrm{CP}-5 \mathrm{~B}_{\mathrm{A}}, 3 \mathrm{CP}-10 \mathrm{~B}_{\mathrm{A}}, 4 \mathrm{CP}-15 \mathrm{~B}_{\mathrm{A}}$. b Histogram of pore-size distribution of the investigated samples

Therefore, TEM analysis with a higher microscope magnification was performed. Only for the sample $\mathrm{CP}-5 \mathrm{~B}_{\mathrm{A}}$ (Fig. 4d) it was possible to obtain a clear image showing that both intercalated and exfoliated nanocomposites are present.

\section{Textural properties}

The results obtained by mercury intrusion porosimetry are presented as cumulative pore-size distribution curves and corresponding histograms for the copolymer and the nanocomposites in Fig. 5a, b, respectively. 


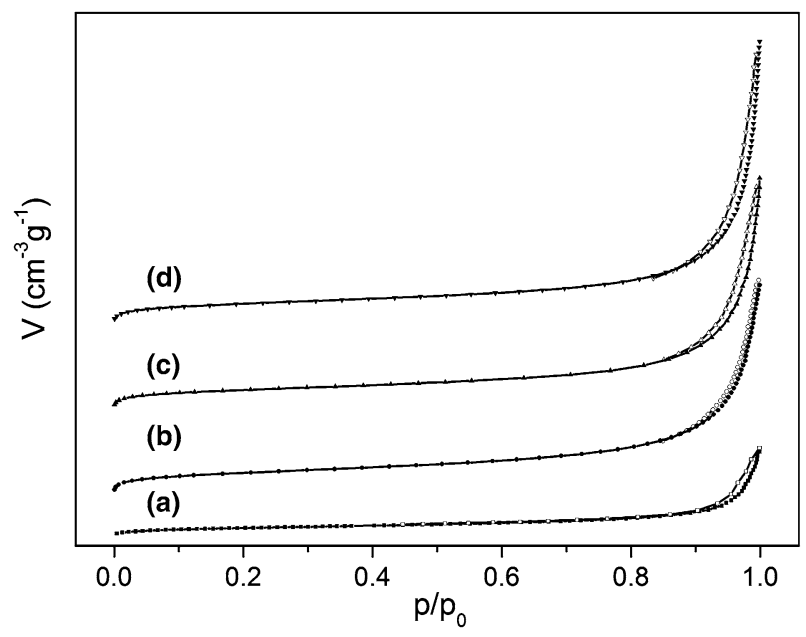

Fig. 6 Adsorption-desorption isotherms of: a CP, b CP-5B $\mathrm{B}_{\mathrm{A}}, \mathbf{c} \mathrm{CP}-10 \mathrm{~B}_{\mathrm{A}}, \mathbf{d} \mathrm{CP}-15 \mathrm{~B}_{\mathrm{A}}$

Cumulative pore-size distribution curves for the copolymer and nanocomposites had an inverse S shape with a clearly defined inflection point. This point was used to determine the most dominant diameter, $d_{\max }$. The cumulative pore-size distribution curve for the copolymer has a plateau in the area of mesopores $(<50 \mathrm{~nm})$. On the other hand, the curves for all nanocomposites have a constant increase in the mesoporous area instead of a plateau. Such curve shapes suggest the presence of smaller mesopores and micropores that can be better analyzed by $\mathrm{N}_{2}$ physisorption method as outlined below (see Fig. 6).

In histogram (Fig. 5b) are given four ranges of pore diameters: mesoporous $(7.5-50 \mathrm{~nm})$ and three in macroporous region 50-200, 200-1,000 and >1,000 nm. In this manner it is easier to analyze changes in pore-size distribution. With the increase of introduced bentonite the occurrence of pores with smaller diameter increased. For CP the most abundant are macropores in range $50-100 \mathrm{~nm}$. This trend remain at $\mathrm{CP}-5 \mathrm{~B}_{\mathrm{A}}$, while in samples with 10 and $15 \%$ of introduced acid modified bentonite mesopores gave the main contribution to total pore volume. This phenomenon leads to increase in $S_{\mathrm{Hg}}$ of these samples, which is illustrated in Table 1 where textural properties obtained by mercury intrusion porosimetry are summarized.

By comparison of the results obtained for the copolymer and the nanocomposites it can be concluded that all textural properties were affected by the incorporation of the acid-modified bentonite. The specific surface areas obtained by $\mathrm{Hg}$-porosimetry and $d_{\max }$ of the nanocomposites significantly differed from those obtained for CP. The $d_{\max }$ of the nanocomposites decreased with the increase of the introduced bentonite $\left(\mathrm{CP}-5 \mathrm{~B}\right.$ A and $\left.\mathrm{CP}-10 \mathrm{~B}_{\mathrm{A}}\right)$. With a further increase of incorporated bentonite $\left(\mathrm{CP}-15 \mathrm{~B}_{\mathrm{A}}\right)$ the change in $d_{\max }$ value is not significant.

Therefore, depending on future application of synthesized nanocomposite the amount of introduced bentonite should be adjusted. If an enhanced specific surface area and smaller pore diameters are desired $\mathrm{CP}-10 \mathrm{~B}_{\mathrm{A}}$ would be an appropriate 
Table 1 Results obtained from mercury intrusion porosimetry

\begin{tabular}{lccc}
\hline Sample & $S_{\mathrm{Hg}}\left(\mathrm{m}^{2} / \mathrm{g}\right)$ & $V_{\mathrm{p}}\left(\mathrm{cm}^{3} / \mathrm{g}\right)$ & $d_{\max }(\mathrm{nm})$ \\
\hline $\mathrm{CP}$ & 33 & 1.06 & 170 \\
$\mathrm{CP}-5 \mathrm{~B}_{\mathrm{A}}$ & 89 & 1.35 & 107 \\
$\mathrm{CP}-10 \mathrm{~B}_{\mathrm{A}}$ & 107 & 1.06 & 58 \\
$\mathrm{CP}-15 \mathrm{~B}_{\mathrm{A}}$ & 108 & 0.96 & 60 \\
\hline
\end{tabular}

$S_{H g}$ specific surface area according to Hg-porosimetry, $V_{p}$ total pore volume, $d_{\max }$ the most dominant diameter

Table 2 Results obtained from nitrogen adsorption-desorption isotherms

\begin{tabular}{lllll}
\hline Sample & $C_{\text {BET }}$ & $S_{\text {BET }}\left(\mathrm{m}^{2} / \mathrm{g}\right)$ & $V_{0.98}\left(\mathrm{~cm}^{3} / \mathrm{g}\right)$ & $V_{\text {meso }}\left(\mathrm{cm}^{3} / \mathrm{g}\right)$ \\
\hline $\mathrm{CP}$ & 42 & 26 & 0.06 & 0.05 \\
$\mathrm{CP}-5 \mathrm{~B}_{\mathrm{A}}$ & 85 & 67 & 0.21 & 0.13 \\
$\mathrm{CP}-10 \mathrm{~B}_{\mathrm{A}}$ & 91 & 59 & 0.20 & 0.12 \\
$\mathrm{CP}-15 \mathrm{~B}_{\mathrm{A}}$ & 77 & 62 & 0.22 & 0.14
\end{tabular}

$C_{B E T}$ constant in BET model, $S_{B E T}$ specific surface area in mesoporous region according to BET model, $V_{0.98}$ total pore volume according to Gurvitch method for $p / p_{0}=0.98, V_{\text {meso }}$ mesopore volume

choice. On the other hand, $\mathrm{CP}-5 \mathrm{~B}_{\mathrm{A}}$ should be synthesized if a less expressed improvement of the specific surface area and a moderate diminishing of the poresize diameters are required, but the increase in total pore volume and porosity is the most significant issue.

To discuss the impact of incorporation of $\mathrm{B}_{\mathrm{A}}$ on the micro and mesoporous structures of nanocomposites the low temperature physisorption of $\mathrm{N}_{2}$ was performed and the appropriate isotherms are given in Fig. 6.

The synthesized samples had a weakly pronounced hysteresis loop and capillary condensation due to the weak adsorbate-adsorbent interaction [53]. It can be observed that bentonite incorporation led to a negligible increase in the micropores. Isotherms obtained for different nanocomposites are almost identical, except in the macroporous region.

From the obtained isotherms using the BET-model, values for the $C_{\mathrm{BET}}$ constant and $S_{\mathrm{BET}}$ (specific surface area in mesoporous interval of pore diameters) were calculated for all samples and the results are given in Table 2. The total pore volume $\left(V_{0.98}\right)$ calculated according to the Gurvitch method and results obtained using the Barrett, Joyner, Halenda method for pore volume in the mesoporous region are also given in Table 2.

These results also support the results obtained by mercury intrusion porosimetry that incorporation of bentonite has a great impact on the textural properties of nanocomposites. The total pore volume increased approx. three times in comparison to $\mathrm{CP}$, while the mesopore volume and $S_{\mathrm{BET}}$ increased approx. twice for all investigated nanocomposites. In general, the variation of the amount of incorporated bentonite had a small impact on the textural properties in the mesoporous area $\left(S_{\mathrm{BET}}, V_{\mathrm{meso}}\right)$. On the other hand, incorporation of bentonite into the copolymer 
matrix significantly increased the $V_{0.98}$ and $S_{\mathrm{BET}}$ of the nanocomposites in comparison with the copolymer. Based on both methods for analysis of the textural properties it can be stated that the most dominant pores in the nanocomposites were macropores. Therefore, nanocomposites synthesized by suspension copolymerization retained macroporosity and the field of applications of macroporous copolymers can therefore be extended to this novel type of nanocomposites.

\section{Conclusion}

Macroporous poly(GMA-co-EGDMA) and its nanocomposites with different amounts of acid-modified bentonite $\left(\mathrm{B}_{\mathrm{A}}\right)$ were prepared by radical suspension copolymerization and denoted $\mathrm{CP}, \mathrm{CP}-5 \mathrm{~B}_{\mathrm{A}}, \mathrm{CP}-10 \mathrm{~B}_{\mathrm{A}}$ and $\mathrm{CP}-15 \mathrm{~B}_{\mathrm{A}}$, according to the amount of $\mathrm{B}_{\mathrm{A}}$ introduced into the reaction mixture. The obtained materials were characterized by IR spectroscopy, SEM, TEM, mercury intrusion porosimetry and nitrogen physisorption. Incorporation of $\mathrm{B}_{\mathrm{A}}$ into the copolymer matrix was confirmed by IR and TEM. TEM images confirmed the formation of nanocomposites in the form of both intercalated and exfoliated nanocomposites. The specific surface area and total pore volume of PCNs increased in both the macroporous and the mesoporous area of pore diameters. The incorporation of bentonite resulted in a shift of pores toward pores with smaller diameters. In general, all textural properties of synthesized nanocomposites significantly differed from those of the copolymer. On the other hand, the difference in textural properties between nanocomposites with varied amount of introduced acid-modified bentonite was less expressed. The obtained nanocomposites retained macroporosity and might be used in many applications that involve macroporous copolymers.

Acknowledgments This study was supported by the Ministry of Education and Science of the Republic of Serbia (Projects III 45001 and III 43009).

\section{References}

1. Kumara AP, Depana D, Tomerb NS, Singha RP (2009) Nanoscale particles for polymer degradation and stabilization: trends and future perspectives. Prog Polym Sci 34:479-515

2. Carastan DJ, Demarquette NR (2006) Microstructure of nanocomposites of styrenic polymers. Macromol Symp 233:152-160

3. Ganguly A, Bhowmick AK (2008) Sulfonated styrene-(ethylene-co-butylene)-styrene/montmorillonite clay nanocomposites: synthesis, morphology, and properties. Nanoscale Res Lett 3:36-44

4. Borthakur LJ, Das D, Dolui SK (2010) Development of core-shell nano composite of poly(styreneco-methyl acrylate) and bentonite clay by ultra sonic assisted mini-emulsion polymerization. Mater Chem Phys 124:1182-1187

5. Carastan DJ, Vermogen A, Masenelli-Varlot K, Demarquette NR (2010) Quantification of clay dispersion in nanocomposites of styrenic polymers. Polym Eng Sci 50:257-267

6. Morgan AB, Gilman JW (2003) Characterization of polymer-layered silicate (clay) nanocomposites by transmission electron microscopy and X-ray diffraction: a comparative study. J Appl Polym Sci 87:1329-1338

7. Çelik M, Önal M (2004) Synthesis and characterization of poly(glycidyl methacrylate)/Na-montmorillonite nanocomposites. J Appl Polym Sci 94:1532-1538 
8. Ray SS, Okamoto M (2003) Polymer/layered silicate nanocomposites: a review from preparation to processing. Prog Polym Sci 28:1539-1641

9. Ray SS, Bandyopadhyay J, Bousmina M (2007) Thermal and thermomechanical properties of poly[(butylene succinate)-co-adipate] nanocomposite. Polym Degrad Stab 92:802-812

10. Thelakkadan AS, Coletti G, Guastavino F, Fina A (2012) Effect of clay dispersion methods on the mechano-dynamical and electrical properties of epoxy-organoclay nanocomposites. Polym Bull. doi: 10.1007/s00289-012-0815-X

11. Li Y, Zhao B, Xie S, Zhang S (2003) Synthesis and properties of poly(methyl methacrylate)/ montmorillonite (PMMA/MMT) nanocomposites. Polym Int 52:892-898

12. Someya Y, Shibata M (2005) Morphology, thermal, and viscoelastic properties of poly(glycidyl methacrylate-co-methyl methacrylate)-based nanocomposites with various organo-modified clays. Polymer 46:4891-4898

13. Djouani F, Herbst F, Chehimi MM, Benzarti K (2011) Synthesis, characterization and reinforcing properties of novel, reactive clay/poly(glycidyl methacrylate) nanocomposites. Constr Build Mater 25:424-431

14. Okamoto M, Morita S, Taguchi H, Kim YH, Kotaka T, Tateyama H (2000) Synthesis and structure of smectic clay/poly(methyl methacrylate) and clay/polystyrene nanocomposites via in situ intercalative polymerization. Polymer 41:3887-3890

15. Sedláková Z, Pleštil J, Baldrian J, Šlouf M, Holub P (2009) Polymer-clay nanocomposites prepared via in situ emulsion polymerization. Polym Bull 63:365-384

16. Fischer H (2003) Polymer nanocomposites: from fundamental research to specific applications. Mat Sci Eng C-Bio S 23:763-772

17. Okamotoa M, Moritaa S, Kima YH, Kotakaa T, Tateyamab H (2001) Dispersed structure change of smectic clay/poly(methyl methacrylate) nanocomposites by copolymerization with polar comonomers. Polymer 42:1201-1206

18. Zeng C, Lee LJ (2001) Poly(methyl methacrylate) and polystyrene/clay nanocomposites prepared by in situ polymerization. Macromolecules 34:4098-4103

19. Djouani F, Herbst F, Chehimi MM, Benzarti K (2010) Preparation of exfoliated clay/polymer nanocomposites via organosilane grafting and in situ ATRP of glycidyl methacrylate. Surf Interface Anal 42:1019-1024

20. Oliveira CFP, Carastan DJ, Demarquette NR, Fechine GJM (2008) Photooxidative behavior of polystyrene-montmorillonite nanocomposites. Polym Eng Sci 48:1511-1517

21. Huang X, Brittain WJ (2001) Synthesis and characterization of PMMA nanocomposites by suspension and emulsion polymerization. Macromolecules 34:3255-3260

22. Alexandre M, Dubois P (2000) Polymer-layered silicate nanocomposites: preparation, properties and uses of a new class of materials. Mat Sci Eng R 28:1-63

23. Paul DR, Robeson LM (2008) Polymer nanotechnology: nanocomposites. Polymer 49:3187-3204

24. Bharadwaj RK, Mehrabi AR, Hamilton C, Trujillo C, Murga M, Fan R, Chavira A, Thompson AK (2002) Structure-property relationships in cross-linked polyester-clay nanocomposites. Polymer 43:3699-3705

25. Suh DJ, Lim YT, Park OO (2000) The property and formation mechanism of unsaturated polyesterlayered silicate nanocomposite depending on the fabrication methods. Polymer 41:8557-8563

26. Arrua RD, Strumia MC, Alvarez Igarzabal CI (2009) Macroporous monolithic polymers: preparation and applications. Materials 2:2429-2466

27. De Santa Maria LC, de Aguiar AP, Aguiar MRMP, Jandrey AC, Guimarães PIC, Nascimento LG (2004) Microscopic analysis of porosity of 2-vinylpyridine copolymer networks 1 . Influence of diluent. Mater Lett 58:563-568

28. Gawdzik B, Maciejewska M (2002) Influence of diluent composition on the porous structure of methacrylate copolymers. J Polym Sci Pol Chem 40:3079-3085

29. Okay O (2000) Macroporous copolymer networks. Prog Polym Sci 25:711-779

30. Unsal E, Irmak T, Durusoy E, Tuncel M, Tuncel A (2006) Monodisperse porous polymer particles with polyionic ligands for ion exchange separation of proteins. Anal Chim Acta 570:240-248

31. Normatov J, Silverstein MS (2007) Silsesquioxane-cross-linked porous nanocomposites synthesized within high internal phase emulsions. Macromolecules 40:8329-8335

32. Marinović S, Vuković Z, Nastasović A, Milutinović-Nikolić A, Jovanović D (2011) Poly(glycidyl methacrylate-co-ethylene glycol dimethacrylate)/clay composites. Mater Chem Phys 128:291-297

33. Marinović S, Milutinović-Nikolić A, Žunić M, Vuković Z, Maksin D, Nastasović A, Jovanović D (2011) Porous glycidyl methacrylate-bentonite composite. Russ J Phys Chem A 85:2386-2391 
34. Jovanović S, Nastasović A, Jovanović N, Jeremić K (1996) Targeted porous structure of macroporous copolymers based on glycidyl methacrylate. Mater Sci Forum 214:155-162

35. Vuković Z, Milutinović-Nikolić A, Rozić Lj, Rosić A, Nedić Z, Jovanović D (2006) The influence of acid treatment on the composition of bentonite. Clays Clay Miner 54:697-702

36. Vuković Z, Milutinović-Nikolić A, Krstić J, Abu-Rabi A, Novaković T, Jovanović D (2005) The influence of acid treatment on the nanostructure and textural properties of bentonite Clays. Mater Sci Forum 494:339-344

37. Nastasović A, Onjia A, Milonjić S, Vuković Z, Jovanović S (2005) Characterization of glycidyl methacrylate based copolymers by inverse gas chromatography under finite surface coverage. Macromol Mater Eng 290:884-890

38. Nastasović A, Sandić Z, Suručić Lj, Maksin D, Jakovljević D, Onjia A (2009) Kinetics of hexavalent chromium sorption on amino-functionalized macroporous glycidyl methacrylate copolymer. J Hazard Mater 171:153-159

39. Nastasović A, Jovanović S, Đorđević D, Onjia A, Jakovljević D, Novaković T (2004) Metal sorption on macroporous poly(GMA-co-EGDMA) modified with ethylene diamine. React Funct Polym 58:139-147

40. Sandić Z, Nastasović A, Jović-Jovičić N, Milutinović-Nikolić A, Jovanović D (2011) Sorption of textile dye from aqueous solution by macroporous amino-metal sorption on macroporous poly(GMAco-EGDMA) modified with ethylene diamine functionalized copolymer. J Appl Polym Sci 121: 234-242

41. Maksin D, Hercigonja R, Lazarević M, Žunić M, Nastasović A (2012) Modeling of kinetics of pertechnetate removal by amino-functionalized glycidyl methacrylate copolymer. Polym Bull 68: $507-528$

42. Nastasović A, Sandić Z, Maksin D, Onjia A, Milutinović-Nikolić A, Jovanović D (2011) Macroporous and non-porous amino-functionalized glycidyl methacrylate based copolymers for hexavalent chromium sorption. In: Salden MP (ed) Chromium: environmental, medical and materials studies. Nova Science publishers, New York, pp 155-172

43. Miletić N, Rohandi R, Vuković Z, Nastasović A, Loos K (2009) Surface modification of macroporous poly(glycidyl methacrylate-co-ethylene glycol dimethacrylate) resins for improved Candida Antarctica lipase B immobilization. React Funct Polym 69:68-75

44. Webb PA, Orr C (1997) Analytical methods in fine particle technology. Micrometrics Instrument Corporation, Norcross

45. Gregg SH, Sing KS (1967) Adsorption, surface area and porosity. Academic Press, New York

46. Nastasović A, Jakovljević D, Sandić Z, Đorđević D, Malović Lj, Kljajević S, Marković J, Onjia A (2007) Amino-functionalized glycidyl methacrylate based macroporous copolymers as metal ion sorbents. In: Barroso MI (ed) Reactive and functional polymers research advances. Nova Science Publishers, New York, pp 79-112

47. Jiang X, Tu W (2010) Stable poly(glycidyl methacrylate-co-ethylene glycol dimethacrylate) microspheres via precipitation polymerization. J Appl Polym Sci 115:963-968

48. Madejová J, Komadel P (2001) Baseline studies of the clay minerals society source clays: infrared methods. Clays Clay Miner 49:410-432

49. Christidis GE, Scott PW, Dunham AC (1997) Acid activation and bleaching capacity of bentonites from the islands of Milos and Chios, Aegean, Greece. Appl Clay Sci 12:329-347

50. Komadel P, Madejová J (2006) Acid activation of clay minerals. In: Bergaya F, Theng BKG, Lagaly $\mathrm{G}$ (eds) Handbook of clay science, developments in clay science. Elsevier, Amsterdam, pp 263-287

51. Gokmen MT, Du Prez FE (2012) Porous polymer particles: A comprehensive guide to synthesis, characterization, functionalization and applications. Prog Polym Sci 37:365-405

52. Sherrington DC (1998) Preparation, structure and morphology of polymer supports. Chem Commun 2275-2286

53. Rouquerol F, Rouquerol J, Sing K (1999) Adsorption by powders and porous solids. Academic Press, London 